\title{
Bloodcurdling movies and measures of coagulation: Fear Factor crossover trial
}

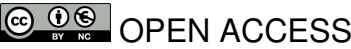

\author{
Banne Nemeth medical doctor ${ }^{12}$, Luuk J J Scheres medical doctor ${ }^{13}$, Willem M Lijfering postdoctoral \\ researcher $^{1}$, Frits $\mathrm{R}$ Rosendaal professor of clinical epidemiology ${ }^{14}$
}

'Department of Clinical Epidemiology, Leiden University Medical Centre, 2300 RC, Leiden, Netherlands; ${ }^{2}$ Department of Orthopaedic Surgery, Leiden University Medical Centre, Leiden, Netherlands; ${ }^{3}$ Department of Vascular Medicine, Academic Medical Centre, Amsterdam, Netherlands; ${ }^{4}$ Einthoven Laboratory for Experimental Vascular Medicine, Leiden University Medical Centre, Leiden, Netherlands

\begin{abstract}
Objective To assess whether, as has been hypothesised since medieval times, acute fear can curdle blood.

Design Crossover trial.

Setting Main meeting room of Leiden University's Department of Clinical Epidemiology, the Netherlands, converted to a makeshift cinema.

Participants 24 healthy volunteers aged $\leq 30$ years recruited among students, alumni, and employees of the Leiden University Medical Center: 14 were assigned to watch a frightening (horror) movie followed by a non-threatening (educational) movie and 10 to watch the movies in reverse order. The movies were viewed more than a week apart at the same time of day and both lasted approximately 90 minutes.
\end{abstract}

Main outcome measures The primary outcome measures were markers, or "fear factors" of coagulation activity: blood coagulant factor VIII, D-dimer, thrombin-antithrombin complexes, and prothrombin fragments $1+2$. The secondary outcome was participant reported fear experienced during each movie using a visual analogue fear scale.

Results All participants completed the study. The horror movie was perceived to be more frightening than the educational movie on a visual analogue fear scale (mean difference $5.4,95 \%$ confidence interval 4.7 to 6.1). The difference in factor VIII levels before and after watching the movies was higher for the horror movie than for the educational movie (mean difference of differences $11.1 \mathrm{lU} / \mathrm{dL}$ (111 IU/L), 95\% confidence interval 1.2 to $21.0 \mathrm{IU} / \mathrm{dL}$ ). The effect of either movie on levels of thrombin-antithrombin complexes, D-dimer, and prothrombin fragments $1+2$ did not differ.
Conclusion Frightening (in this case, horror) movies are associated with an increase of blood coagulant factor VIII without actual thrombin formation in young and healthy adults.

Trial registration ClinicalTrials.gov NCT02601053.

\section{Introduction}

Nothing in life is to be feared, it is only to be understood. Now is the time to understand more, so that we may fear less. Marie Curie, 1867-1934'

For centuries the term "bloodcurdling" has been used to describe feeling extreme fear under frightening situations. ${ }^{2}$ Similar terms are used in other countries, such as "das blut in den Adern erstarrt" in Germany, "à vous glacer le sang" in France, and "bloedstollend" in the Netherlands. The term dates back to medieval times and is based on the concept that fear or horror would "run the blood cold" or "curdle" (congeal) blood. ${ }^{3}$ The validity of this theory has, however, never been studied. Several studies have explored the effects of physical stress on the coagulation system. ${ }^{4}$ For example, chronic anxiety in patients with psychiatric disorders (and associated therapies which may influence blood coagulation) is associated with increased levels of coagulation markers, ${ }^{56}$ and increased coagulation activity has been observed in healthy volunteers after bungee jumping. ${ }^{7}$ Yet the effects of excitement and profound physical activity are not necessarily equal to those of acute fear, because, for example, actions such as bungee jumping are performed voluntarily and this was seen as deviating from an ideal study design. ${ }^{8}$ 
We investigated the effect of acute fear without physical exercise on markers of coagulation. We hypothesised that acute fear activates the coagulation system and that this poses an important evolutionary benefit, by preparing the body for blood loss during life threatening situations.

\section{Methods}

We recruited 24 healthy volunteers aged $\leq 30$ years from among students, alumni, and employees of the Leiden University Medical Centre. We excluded those who were taking prescribed drugs, pregnant, using hormonal contraceptives, had a history of thrombosis, and had had surgery or been immobilised with a cast in the past two months.

One group $(\mathrm{n}=14)$ were assigned to watch the horror movie Insidious (2010) ${ }^{9}$ (www.imdb.com/video/imdb/vi1929288729? ref_=tt_pv_vi_aiv_2) followed by the documentary $A$ Year in Champagne (2014). ${ }^{10}$ The other group $(\mathrm{n}=10)$ watched the movies in reverse order (see supplementary file for authors' descriptions of these movies). As movie nights were set on specific dates, group allocation was based on availability of the participants. Each movie lasted approximately 90 minutes and they were shown one week apart at the same time of day (fig $1 \Downarrow)$. Participants were seated in comfortable chairs and were not aware in advance of either the movie genre or the study hypothesis; we provided them with a leaflet explaining that the study aimed to determine the effects on coagulation of sitting still and watching movies.

The movies were shown at the Department of Clinical Epidemiology's main meeting room, which for the purposes of this study was transformed into a home-style cinema. The room has a non-threatening, welcoming atmosphere. Participants were asked to avoid alcohol and tobacco on movie days. To reduce the risk of confounding by superstition, no movies were shown during a full moon or on Friday the 13th. The participants provided written informed consent.

\section{Laboratory measurements}

Within 15 minutes before each movie, we took blood samples from each participant's antecubital vein and used the contralateral arm for the second blood sample taken within 15 minutes after each movie.

Markers of coagulation activity (or potential "fear factors") were blood coagulant factor VIII (IU/dL), D-dimer ( $\mathrm{ng} / \mathrm{mL}$ ), thrombin-antithrombin complexes $(\mu \mathrm{g} / \mathrm{L})$, and prothrombin fragments $1+2(\mathrm{pmol} / \mathrm{L})$. Blood samples were drawn in vacuum tubes containing $0.105 \mathrm{M}$ sodium citrate and centrifuged at 2500 $\mathrm{g}$ for 10 minutes at $18^{\circ} \mathrm{C}$ within one hour of venepuncture. After aliquoting, the samples were stored at $-80^{\circ} \mathrm{C}$. All markers were determined within one batch. We measured prothrombin fragments $1+2$ and thrombin-antithrombin complexes in duplicate and the samples were measured using a sandwich-type enzyme linked immunosorbent assay (Siemens, Marburg, Germany). Coagulant factor VIII and D-dimer levels were measured using the TOP analyser (Werfen Instrumentation Laboratory, Barcelona, Spain). The laboratory technicians were not aware of which movie corresponded to which blood sample.

\section{Fear scale and questionnaire}

After each movie the participants completed a visual analogue fear scale, designed specifically for this study. This scale estimates the degree of fear experienced while watching a movie, ranging from 0 (no fear at all) to 10 (worst fear imaginable). Additionally, participants reported whether they had already seen the movie and rated it on a scale from 0 (worst ever) to 10 (best ever). Finally, the participants completed a general questionnaire on lifestyle and favourite movie genre.

\section{Sample size calculation}

We calculated the sample size required for evaluation of coagulant factor VIII activity (two sided test, $\alpha=0.05, \beta=0.90$ ) and determined that 23 participants would be required to observe an increase of $15 \mathrm{IU} / \mathrm{dL}$ (150 IU/L) or more (assuming a correlation between the difference in measurements at the two time points of 0.7 ). Taking into account possible dropouts, we determined that overall 24 participants would be required.

\section{Statistical analyses}

We summarised personal and baseline data as means with standard deviations, or proportions. Using a paired $t$ test we compared the difference between the mean change in levels of coagulation markers (before and after watching the horror movie compared with before and after watching the educational movie). For the visual analogue fear scale we reported the mean change and $95 \%$ confidence intervals. At baseline (before both movies) the groups had similar levels of coagulation factors. Therefore we considered a carry-over effect to be absent and pooled the results of both groups by movie genre.

\section{Results}

\section{Participants and recruitment}

The table shows the baseline characteristics of the study sample. Participants watched the movies, which started around $7 \mathrm{pm}$ (15 minutes either way) and ended at around $8.30 \mathrm{pm}$ (15 minutes either way) on 29 July and 4, 5, and 11 August. According to the availability of participants, 14 were assigned to the watch the horror movie first and 10 to watch the educational movie first.

Participants perceived the horror movie as being frightening, with a mean score on the visual analogue fear scale of 5.4 (SD 1.7). The corresponding values for the educational movie were 0.0 (SD 0.2): the mean difference between scores was 5.4 (95\% confidence interval 4.7 to 6.1 ).

\section{Fear factor analyses}

Three participants were excluded from the primary analyses. In two, a sample was visibly haemolytic. Therefore these results were considered unreliable because in the case of haemolysis, various measurements (coagulation factors among them) are known to be inaccurate owing to degradation of red blood cells. The third participant was tense before the first blood sample was taken (before watching the educational movie); in an attempt to relax before the second blood sample was taken he ingested a family pack of chocolates. He subsequently fainted while blood was being taken after the educational movie.

Fainting was not observed in association with the second, horror, movie. Since the assumption for a crossover trial (that is, similar circumstances except for the intervention) was clearly not met, we regarded the results as unusable (coagulant factor VIII levels before and after the educational movie were $132 \mathrm{IU} / \mathrm{dL}$ and 346 IU/dL, respectively, and before and after the horror movie were $109 \mathrm{IU} / \mathrm{dL}$ and $123 \mathrm{IU} / \mathrm{dL}$, respectively).

The mean baseline levels of coagulant factor VIII of the remaining 21 participants were similar before both the horror movie and the educational movie (mean difference $-2.9 \mathrm{IU} / \mathrm{dL}$, $95 \%$ confidence interval -10.1 to 4.2 ). However, the mean change in levels (difference between levels before and after the 
movie) was higher after the horror movie than after the educational movie (mean difference 11.1 IU/dL, 1.2 to 21.0, fig $2 \Downarrow)$. Coagulant factor VIII levels increased in $12(57 \%)$ participants during the horror movie, but only in $3(14 \%)$ during the educational movie. Levels decreased in 18 (86\%) participants during the educational movie, but only in $9(43 \%)$ during the horror movie.

The mean D-dimer levels of participants were similar before watching the horror and educational movie. The mean change in levels before and after the educational movie was -35.1 $\mathrm{ng} / \mathrm{mL}$ (SD 63.0) and before and after the horror movie was -31.8 (SD 109.3). Therefore no effect of acute fear on D-Dimer levels was observed (fig $2 \Downarrow$ ): the mean difference was 3.33 $\mathrm{ng} / \mathrm{mL}$ (95\% confidence interval -37.1 to 43.8 ). There was also no effect on levels of thrombin-antithrombin complexes: mean difference of differences $-0.54 \mu \mathrm{g} / \mathrm{L}$ (95\% confidence interval -2.5 to 1.4 , fig $2 \Downarrow$ ). All but two of the measurements for prothrombin fragments $1+2$ levels before and after both movies were less than $200 \mathrm{pmol} / \mathrm{L}$. The mean change in levels (fig $2 \Downarrow$ ) before and after the educational movie was -10.2 (median -1.0) $\mathrm{pmol} / \mathrm{L}$ and before and after the horror movie was -23.7 (median -21) $\mathrm{pmol} / \mathrm{L}$.

\section{Discussion}

In this crossover study we found that watching horror, or "bloodcurdling," movies was associated with an increase in blood coagulant factor VIII. The mean increase in factor VIII levels of $11.1 \mathrm{IU} / \mathrm{dL}$ associated with acute fear could be clinically relevant, as every $10 \mathrm{IU} / \mathrm{dL}$ increase in coagulant factor VIII levels is associated with a $17 \%$ (95\% confidence interval $7 \%$ to $28 \%$ ) increase in the risk of venous thrombosis. ${ }^{11}$ Levels of D-dimer, thrombin-antithrombin complexes, and prothrombin factors $1+2$ did not prove to be fear factors. This indicates that although the coagulation cascade was influenced by acute fear, this did not lead to the formation of thrombin (thrombin-antithrombin complexes and prothrombin factors $1+2)$ and subsequent fibrin formation (D-dimer).

\section{Limitations of this study}

A limitation of the study could be the magnitude of fear induced by the movie genre. Although some participants scored 7 or 8 on the visual analogue fear scale, there is definite room for the enhancement of fear. However, such designs might elicit ethical controversy and would likely be confounded by physical exertion. Secondly, we did not completely reach the intended sample size. Nevertheless, we still found a clear $11.1 \mathrm{IU} / \mathrm{dL}$ (95\% confidence interval 1.2 to 21.0 ) increase in coagulant factor VIII levels after exposure to the horror movie. Thirdly, participants were not randomised by the order in which the movies were watched. Finally, the visual analogue fear scale was not validated.

\section{Implications of this study}

The underlying biological mechanism of acute fear associated with an increase in coagulation activity is still to be unravelled. However, the results of this study might be explained by an adrenergic response, as epinephrine increases the concentrations of coagulant factor VIII. ${ }^{12}$ Also, desmopressin, a vasopressin analogue, has been used to increase coagulation activity in a wide range of bleeding diathesis. ${ }^{13}$ Desmopressin stimulates the release of von Willebrand factor, resulting in increased coagulant factor VIII levels. ${ }^{14}$ Although it is not immediately obvious by which means our results could confer clinical benefits, a broader implication of these study results is that after centuries the term "bloodcurdling" in literature is justified.

\section{Conclusion}

In young and healthy adults, watching bloodcurdling movies is associated with an increase in blood coagulant factor VIII without actual thrombin formation.

We thank Nine Nemeth, Maaike Hermans, and Liesbeth Willems of Brilman-Tuinhof de Moed for their help with blood collection; Petra Noordijk, Annelies Hoenderdos, and Lejla Mahic for laboratory analyses; Selina Wijbenga and Yanna van der Spek for accompanying frightened study participants; and Eva Rosendaal for her expertise in horrorology. We are especially grateful to the volunteers who took part in the study.

Contributors: According to good epidemiological practice, the decision of who would be first and who would be second author was made by randomisation. All authors were involved in the study design, study conduct, data analysis, and revision of the manuscript. All authors read and approved the final manuscript and are guarantors of the paper. Funding: This study was sponsored by the Department of Clinical Epidemiology, Leiden University Medical Center.

Competing interest: All authors have completed the ICMJE uniform disclosure form at www.icmje.org/coi_disclosure.pdf and declare: no support from any organisation for the submitted work; no financial relationships with any organisations that might have an interest in the submitted work in the previous three years; no other relationships or activities that could appear to have influenced the submitted work.

Ethical approval: This study was approved by the medical ethics committee of Leiden University Medical Center.

Transparency: The guarantors affirm that the manuscript is an honest, accurate, and transparent account of the study being reported; that no important aspects of the study have been omitted; and that any discrepancies from the study as planned (and, if relevant, registered) have been explained.

Benarde MA. Our precarious habitat. 2nd ed. Norton, 1973.

2 Anderson S. Collins English dictionary—complete and unabridged. 7th ed. HarperCollins, 2005.

3 Knowles E. Oxford dictionary of phrase and fable. Oxford University Press, 2005: 86-7.

4 Thrall G, Lane D, Carroll D, Lip GYH. A systematic review of the effects of acute psychological stress and physical activity on haemorheology, coagulation, fibrinolysis and platelet reactivity: Implications for the pathogenesis of acute coronary syndromes. Thromb Res 2007;120: 819-47. doi:10.1016/j.thromres.2007.01.004 17321571

5 Geiser F, Meier C, Wegener I. Association between anxiety and factors of coagulation and fibrinolysis. Psychother Psychosom 2008;77: 377-83. doi:10.1159/ 00015151818716423

6 Pitsavos C, Panagiotakos DB, Papageorgiou C, Tsetsekou E, Soldatos C, Stefanadis C Anxiety in relation to inflammation and coagulation markers, among healthy adults: the ATTICA study. Atherosclerosis 2006;185: 320-6. doi:10.1016/j.atherosclerosis.2005.06. 00116005881

7 Van Westerloo DJ, Choi G, Löwenberg EC. Acute stress elicited by bungee jumping suppresses human innate immunity. Mol Med 2011;17: 180-8. doi:10.2119/molmed.2010. 0020421203694

8 Vandenbroucke JP. Bungee-jumping and design of experiments. Lancet 1992;340: 800. doi:10.1016/0140-6736(92)92351-F 1356221

9 Insidious I. Alliance Films, IM Global, Haunted Movies et al, 2010. www.imdb.com/title/ tt1591095/awards?ref_=tt_awd

10 A Year in Champagne. Samuel Goldwyn Films, 2014. www.imdb.com/title/tt3544048/? ref_=fn_al_tt_1

11 Kraaijenhagen RA, in't Anker PS, Koopman MM. High plasma concentration of factor VIIIc is a major risk factor for venous thromboembolism. Thromb Haemost 2000;83: 5-9. 10669145

12 Ingram Gl, Knights SF, Barrow EM, Dejanov II. The rise in factor-8 concentration after infusion of adrenaline. Br J Haematol 1968;15: 326. 5681496

13 Mannucci PM, Ruggeri ZM, Pareti FI, Capitanio A. 1-Deamino-8-d-arginine vasopressin: a new pharmacological approach to the management of haemophilia and von Willebrands' diseases. Lancet 1977:1: 869-72 doi:10.1016/S0140-6736(77)91197-7 67283

14 Mannucci PM. Desmopressin (DDAVP) in the treatment of bleeding disorders: the first 20 years. Blood 1997;90: 2515-21. 9326215

Accepted: 13112015

Published by the BMJ Publishing Group Limited. For permission to use (where not already granted under a licence) please go to http://group.bmj.com/group/rights-licensing/ permissions

This is an Open Access article distributed in accordance with the Creative Commons Attribution Non Commercial (CC BY-NC 3.0) license, which permits others to distribute, 


\section{What is already known on this topic}

As early as medieval times it was thought that fear induced curdling (congealing) of the blood Several studies have reported an increase in coagulation profiles in times of physical or psychological stress

The effect of acute fear on the coagulation system is, however, still to be unravelled

\section{What this study adds}

Exposure of young and healthy adults to horror movies was associated with an increase in coagulant factor VIII levels

No effect was observed on levels of D-dimer, thrombin-antithrombin complexes, or prothrombin fragment $1+2$, suggesting that watching frightening movies is associated with an acute effect on coagulation without actual thrombin formation

A truly relaxing and merry Christmas, without exposure to frightening situations, seems to be advisable to prevent venous thrombosis 


\section{Table}

Table 1| Baseline characteristics of study sample. Values are numbers (percentages) unless stated otherwise

\begin{tabular}{|c|c|}
\hline Characteristics & Study sample $(n=24)$ \\
\hline Men & $16(67)$ \\
\hline Mean (SD) age (years) & $25.9(3.0)$ \\
\hline Mean (SD) height (m) & $1.81(0.12)$ \\
\hline Mean (SD) weight (kg) & $77.6(11.8)$ \\
\hline Mean (SD) body mass index & $23.4(2.5)$ \\
\hline Smokers & $2(8)$ \\
\hline \multicolumn{2}{|l|}{ Cigarettes/day (No) } \\
\hline 1-5 & $1(4)$ \\
\hline $6-10$ & 0 \\
\hline $11-15$ & 0 \\
\hline $16-20$ & $1(4)$ \\
\hline Consume alcohol & $19(78)$ \\
\hline \multicolumn{2}{|l|}{ Alcohol intake (units/wk) } \\
\hline $1-5$ & $7(29)$ \\
\hline $6-10$ & $7(29)$ \\
\hline $11-15$ & $3(12)$ \\
\hline $16-20$ & $1(4)$ \\
\hline $21-25$ & 0 \\
\hline $26-30$ & $1(4)$ \\
\hline Consume coffee & $19(79)$ \\
\hline \multicolumn{2}{|l|}{ Coffee intake (cups/day) } \\
\hline 1-3 & $12(50)$ \\
\hline $4-6$ & $6(25)$ \\
\hline $7-9$ & $1(4)$ \\
\hline \multicolumn{2}{|l|}{ Favourite movie genre } \\
\hline Action & $7(29)$ \\
\hline Adventure & $1(4)$ \\
\hline Thriller & $3(13)$ \\
\hline Romantic comedy & $5(21)$ \\
\hline Science fiction & $2(8)$ \\
\hline Comedy & $4(17)$ \\
\hline Fantasy & $1(4)$ \\
\hline Drama & $1(4)$ \\
\hline Horror movie fan & $5(21)$ \\
\hline \multicolumn{2}{|l|}{ Horror movie } \\
\hline Mean (SD) VAFS score $†$ & $5.4(1.7)$ \\
\hline Mean (SD) movie rating scoreł & $4.25(4.3)$ \\
\hline Seen movie before & $3(12.5)$ \\
\hline \multicolumn{2}{|l|}{ Educational movie } \\
\hline Mean (SD) VAFS score† & $0.0(0.2)$ \\
\hline Mean (SD) movie rating scoreł & $5.1(1.7)$ \\
\hline Seen movie before & $0(0)$ \\
\hline $\begin{array}{l}\text { VAFS=visual analogue fear scale } \\
\text { * Average } 200 \mathrm{~mL} \text { per cup. } \\
\dagger 0 \text { (no fear at all) to } 10 \text { (worst fe } \\
\ddagger 0 \text { (worst ever) to } 10 \text { (best ever }\end{array}$ & $\begin{array}{l}\text { e. } \\
\text { r). }\end{array}$ \\
\hline
\end{tabular}

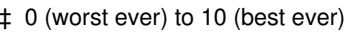




\section{Figures}

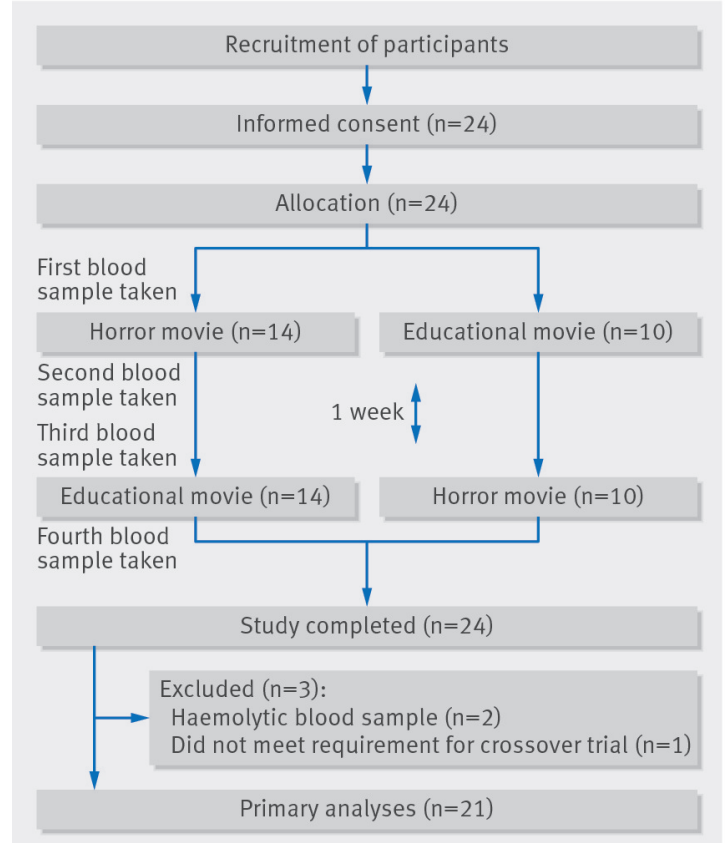

Fig 1 Flow of participants through study 
Horror movie

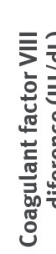

Coagulant factor VIII 20

10

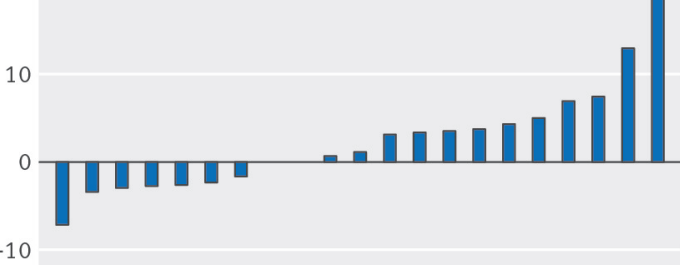

$-20$

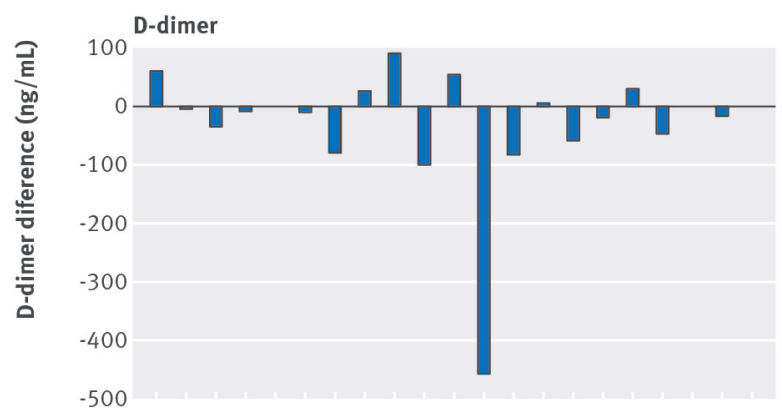

Thrombin-antithrombin complexes

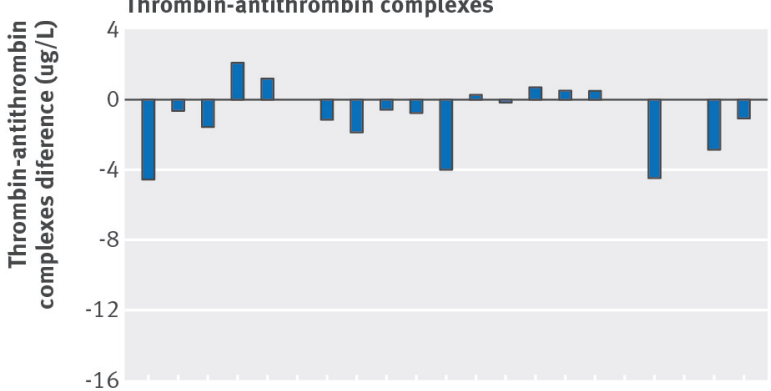

$-16$

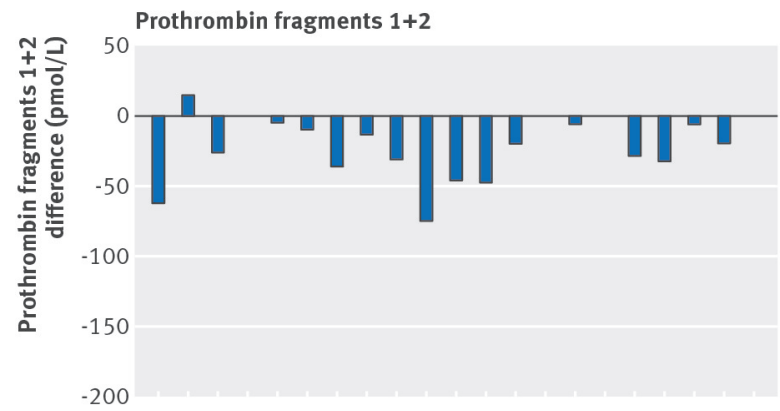

Participants
Educational movie
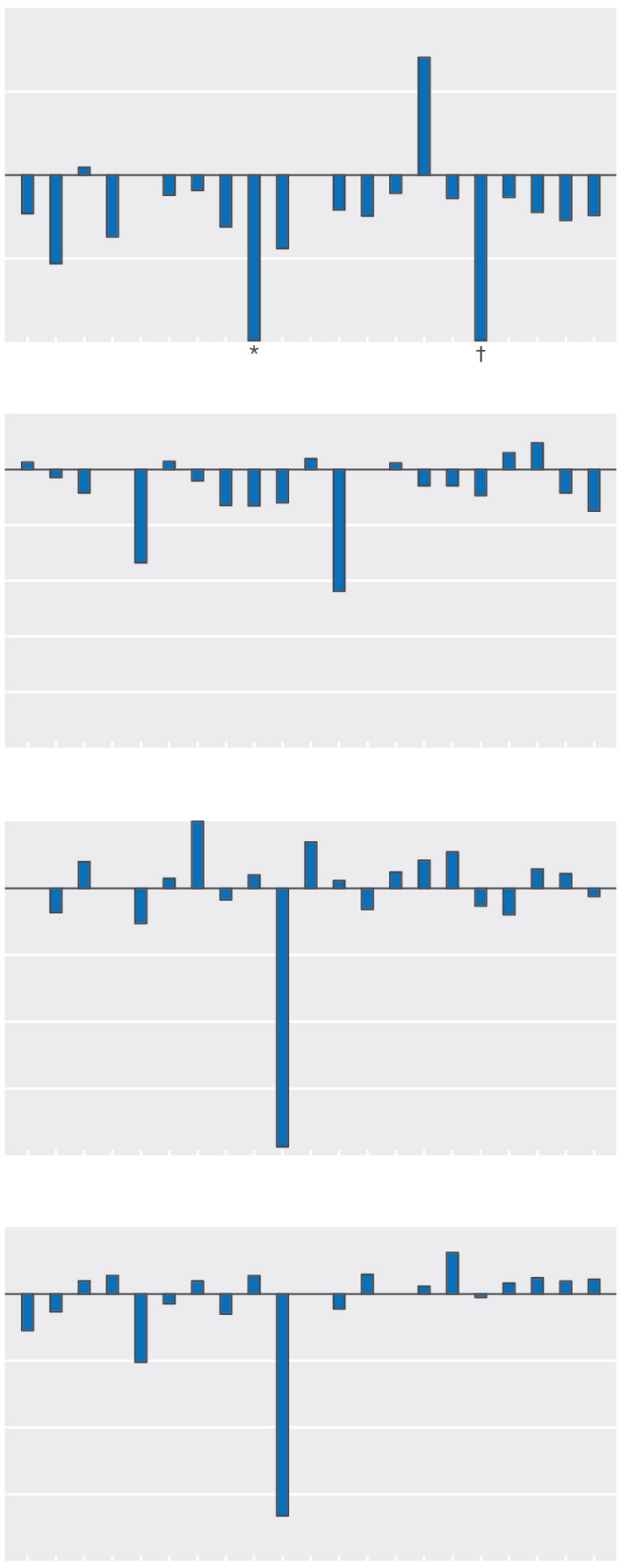

Participants

Fig 2 Absolute mean change in levels of coagulation factor VIII, D-dimer, thrombin-antithrombin complexes, and prothrombin fragments $1+2$ after exposure to a horror and educational movie (ordered by change in levels during watching a horror movie). Vertical bars represent individual participants, with order of participants identical in all graphs. *Difference -96 IU/dL, tdifference $-27 \mathrm{IU} / \mathrm{dL}$ 